\title{
Globalización, política criminal y rumbos del derecho penal en el contexto de la sociedad del riesgo*
}

\author{
Dayán Gabriel López Rojas • Isnel Martínez Montenegro
}

\begin{abstract}
Resumen: La presente investigación se orienta a analizar el impacto que la globalización planetaria genera sobre la política criminal y el derecho penal en la denominada "sociedad del riesgo". Tal problemática constituye uno de los aspectos que mayor preocupación despierta en la agenda criminológica actual, con motivo de los peligros que estas tendencias suponen para el respeto de los derechos y las garantías fundamentales de los ciudadanos, tradicionalmente interpretados como límites al ius puniendi en el contexto de un Estado de derecho. El análisis teórico que aquí se desarrolla representa una investigación a nivel básico, cuyo principal resultado es la caracterización de la política criminal y del derecho penal de nuestros días, y concluye con la formulación de algunas propuestas que se estiman útiles en el propósito de configurar una política criminal coherente y razonable, las cuales pueden generalizarse a cualquier contexto en el que rija un sistema penal de corte democrático.
\end{abstract}

Palabras clave: política criminal; teoría del bien jurídico; globalización

Fecha de recepción: 31 de octubre de 2017 Fecha de evaluación: 25 de junio de 2018

Fecha de aprobación: 25 de junio de 2018

Cómo citar: López Rojas, D. G., \& Martínez Montenegro, I. (2020). Globalización, política criminal y rumbos del derecho penal en el contexto de la sociedad del riesgo. Prolegómenos, 23(45), 15-32. https://doi.org/10.18359/prole.3130

* El presente artículo es resultado de las acciones desarrolladas en el marco del Grupo de Investigación "El Derecho frente a los nuevos cambios sociales" del Departamento de Derecho de la Universidad de Matanzas, Cuba. Se inscribe dentro del Proyecto de Investigación I+D+i Corrupción y delincuencia económica. Estrategias preventivas y reactivas en el contexto de actualización del modelo socio-económico cubano (P7751MT001-001)

Artículo de investigación.

a Académico de la Universidad de Matanzas (Cuba). Doctor en Ciencias Jurídicas de la Universidad de La Habana (Cuba). Magíster en Criminología de la Universidad de La Habana (Cuba). Correo electrónico: dayan.lopez@umcc.cu

b Académico de la Universidad de las Américas y de la Universidad Católica de Temuco (Chile). Magister en Sistema de Justicia Penal por la Universidad de Lleida (España). Doctor en Derecho, Ciencias Políticas y Criminología de la Universidad de Valencia (España). Magíster en Administración de Empresas de la Universidad de Matanzas y Magíster en Derecho de la Economía de la Universidad de La Habana (Cuba). Correo electrónico: isnel.martinez@edu.udla.cl 


\title{
Globalization, Criminal Policy, and Courses of Criminal Law in the Context of Risk Society
}

\begin{abstract}
This research aims at examining the impact that globalization has on criminal policy and criminal law in the so-called "risk society." Such a problem constitutes one of the greatest concerns on the current criminological agenda due to the dangers these trends pose for the respect of the citizens' fundamental rights and guarantees, traditionally interpreted as limits to ius puniendi under the rule of law. The theoretical analysis represents basic level research whose main result is the characterization of today's criminal policy and criminal law. It concludes with some proposals that are deemed useful to shape a coherent and reasonable criminal policy, which can be generalized to any context governed by a democratic criminal system.
\end{abstract}

Keywords: Criminal policy; legally-protected interest theory; globalization.

\section{Globalização, política criminal e rumos do direito penal no contexto da sociedade do risco}

Resumo: Esta pesquisa está orientada a analisar o impacto que a globalização planetária gera sobre a política criminal e o direito penal na denominada "sociedade do risco". Essa problemática constitui um dos aspectos que mais preocupação desperta na agenda criminalística atual, devido aos perigos que essas tendências supõem para o respeito dos direitos e das garantias fundamentais dos cidadãos, tradicionalmente interpretados como limites ao ius puniendi no contexto de um Estado de direito. A análise teórica desenvolvida representa uma pesquisa de nível básico, cujo principal resultado é a caracterização da política criminal e do direito penal de nossos dias. Conclui-se com a formulação de algumas propostas que são consideradas úteis no propósito de configurar uma política criminal coerente e razoável, as quais podem ser generalizadas para qualquer contexto em que um sistema penal de corte democrático opere.

Palavras-chave: política criminal; teoria do bem jurídico; globalização. 


\section{A modo de contextualización}

La globalización constituye, sin duda, el fenómeno sociológico sobre el que más se ha polemizado desde el pasado siglo hasta nuestros días. Sus múltiples perspectivas y niveles de análisis, determinados tanto por los disímiles sectores sobre los que irradia como por su constante evolución, le adjudican dosis de alta complejidad.

Tal situación queda perfectamente ilustrada a partir de las reflexiones de Beck (1998), para quien,

globalización es a buen seguro la palabra (a la vez eslogan y consigna) peor empleada, menos definida, probablemente la menos comprendida, la más nebulosa y políticamente la más eficaz de los últimos tiempos $-\mathrm{y}$ sin duda también de los próximos años-. Como muestran los casos arriba apuntados, es preciso distinguir las diferentes dimensiones de la globalización; a saber [...], las dimensiones de las técnicas de comunicación, las dimensiones ecológicas, las económicas, las de la organización del trabajo, las culturales, las de la sociedad civil, etc. (pp. $28-30)^{1}$.

Si bien su naturaleza difusa impone serias dificultades a la configuración de un concepto

1 En este sentido se pronuncia Martínez (2005) al sostener que "hay un amplio acuerdo sobre la relevancia de la globalización en nuestros días, pero es un acuerdo que tiene mucho de ficticio porque no siempre se habla de lo mismo cuando se habla de la globalización, con lo que la supuesta coincidencia queda reducida a la simple constatación del uso extendido del término [...]. En la literatura pueden encontrarse tantas caracterizaciones como pueda solicitar el más caprichoso de los lectores” (p. 17). acabado $^{2}$, todo intento de comprensión al respecto ha de tomar en cuenta que la globalización, vista desde la arista económica, supone en esencia la mundialización del sistema económico capitalista, de sus componentes, de sus relaciones básicas, de su lógica de funcionamiento y reproducción (Martínez, 2005) $)^{3}$.

Con independencia de que no se esté evaluando un término propiamente jurídico, merecen

2 Refiriéndose a la problemática sobre el análisis de la globalización, afirma Martínez (2005): "Queda un largo camino para llegar a caracterizar satisfactoriamente su continua evolución, entender su lógica y desvelar sus efectos. Algo que, además, no se conseguirá plenamente sin situarla en el seno del nuevo modelo de desarrollo que se está pugnando para formarse ante nuestros ojos, como resultado de la combinación e interacción de las nuevas tecnologías de la información y la comunicación, del avance de la globalización, de la problemática derivada de la sostenibilidad, del ascenso de la financiarización y de la afirmación contradictoria de ciertas opciones institucionales. Será en ese contexto cuando, mejor perpetrados, estaremos en condiciones para retomar cuestiones acuciantes relativas a su gobierno, a los objetivos, a los medios y, por qué no, también a las alternativas” (p. 37).

3 Una visión más holística del fenómeno, con la que se coincide, es la ofrecida por Borja (2001), cuando afirma que "con el término globalización se quiere proporcionar una explicación de la realidad de la vida social y de la vida de los individuos desde una perspectiva planetaria, en un mundo sin fronteras; por un lado, interdependiente e intercomunicado (a pesar de las distancias), y a su vez; por otro lado, independiente de la pertenencia a los pueblos, a las etnias o a las culturas de cada uno de los operadores del sistema económico, político o social” (p. 106). Una caracterización del proceso globalizador, desde una perspectiva integral, puede verse en Ramonet (2000, pp. 27 y ss). 
destacarse algunos caracteres esenciales ${ }^{4}$ del fenómeno en el plano económico, político y comunicacional, en razón a su manifiesto impacto sobre el universo de las relaciones jurídicas (Borja, 2001; Vogel, 2005).

Así, desde el punto de vista económico, la globalización supone la génesis de mercados globales en cuyo escenario los agentes económicos $-\mathrm{y}$ en especial las empresas transnacionales - gozan de un especial protagonismo y dinámica de movimiento respecto a sus elementos básicos (capital, trabajo, bienes y servicios) a escala planetaria, garantizado esto por el ostensible desarrollo tecnológico en materia de transporte, información y comunicaciones. Además, genera una interdependencia de las economías nacionales respecto a otros Estados u organizaciones internacionales, con serios límites a la autonomía en su dirección y gestión.

En el orden político, la mundialización provoca en la actualidad que los Estados nacionales pierdan relevancia política, con evidentes mermas de su soberanía, a consecuencia de dos factores fundamentales; por una parte, la influencia cada vez más creciente de las empresas transnacionales, $y$, por otra, el sometimiento a organizaciones supraestatales como es el caso de la Unión Europea y el Fondo Monetario Internacional, por solo citar dos ejemplos. Esto trae aparejado, como correlato, la emergencia de mecanismos de gobierno global.

Es necesario destacar también el impacto que a nivel mundial han provocado las nuevas tecnologías de la comunicación y de la información - la llamada "globalización de las comunicaciones"-, lo cual ha garantizado que se materialicen las más variadas formas de intercambio mundial, muchas veces de forma instantánea.

4 Resulta imposible aprehender en una investigación de estas características todas las aristas de la globalización; de ahí que solo se intentará una básica caracterización que permita luego analizar y comprender los impactos que genera sobre el derecho penal, y en especial sobre la configuración de la política criminal que se sigue a nivel mundial para reaccionar contra la moderna criminalidad.
Todas estas transformaciones imponen cambios en la dinámica y manifestación de los fenómenos sociales, incluida la cuestión criminal, que en este contexto adquiere formas, matices y protagonistas diferentes ${ }^{5}$.

El desarrollo social y económico de la sociedad moderna, tal y como sostienen Savona y Defeo (como se citan en Blanco, 2012) también muestra un lado amargo en el que los actores sociales han aprendido a explotar los mercados globales, las economías de escala y los efectos de armonización entre las políticas nacionales preventivas y de control. De este modo, la complejidad de la organización criminal es, en suma, una imagen de la moderna complejidad económica y social.

La presente investigación procura analizar los impactos que la globalización genera sobre la política criminal y, consecuentemente, sobre el modo de configurar e interpretar el derecho penal. Si bien se asume como punto de partida la necesidad de armonizar las respuestas penales con las nuevas características del fenómeno criminal contemporáneo, conviene que las agencias de control penal no pierdan de vista los valores, los principios y las garantías básicas que definen la esencia de un derecho penal propio de un Estado de derecho, limitador del poder punitivo y respetuoso de los derechos fundamentales de los ciudadanos.

Desde esta perspectiva, se defienden algunas propuestas encaminadas a legitimar una modernización razonable del derecho penal frente a las nuevas exigencias de protección que emergen en el escenario global, pero siempre desde una visión que equilibre las demandas de seguridad y libertad,

5 El reacomodo que la globalización impone al sistema penal se advierte a partir de la aparición de nuevas formas delictivas, en consonancia con la emergencia de nuevos bienes jurídicos. Al respecto reflexiona Correcher (2013) en el sentido de que "la libre circulación de personas y bienes muebles posibilita la aparición de delitos con elementos de extranjería; el aumento de la actividad económica a nivel global provoca un inevitable número de infracciones penales de tipo económico; los avances en materia de telecomunicaciones facultan la aparición de nuevos tipos delictivos insertos en la criminalidad informática” (p. 86). 
y sin que quepa asumir - con motivo de discursos de emergencia- opciones regresivas que conducen, como es sabido, a respuestas totalitarias.

Esta investigación se realizó a partir de la revisión de fuentes documentales y entrevistas a académicos y criminólogos iberoaméricanos. La información documental obedece a la revisión de la literatura teórica sobre el tema que se encuentra publicada en libros, tesis de estudios de posgrado y documentos de investigación que se informan en distintas revistas de ciencia, técnica e innovación.

Se asociaron los impactos y su correspondencia respecto a la política criminal y el derecho penal en la denominada "sociedad del riesgo". Tal problemática constituye uno de los aspectos que mayor preocupación despierta en la agenda criminológica actual, con motivo de los peligros que estas tendencias suponen para el respeto de los derechos y las garantías fundamentales de los ciudadanos, tradicionalmente interpretados como límites al ius puniendi en el contexto de un Estado de derecho. El análisis teórico que aquí se desarrolla representa una investigación a nivel básico. A su vez, se utilizó un conjunto de operaciones lógicas del pensamiento, tales como el análisis, la síntesis, la generalización y la abstracción, a fin de presentar los presupuestos normativos y los enfoques de género que a partir del estudio se generan.

Con base en los resultados de investigación y del estudio de los nuevos escenarios que surgen como consecuencia de la caracterización de la política criminal y el derecho penal de nuestros días, se logró un soporte bibliográfico puesto al día desde la perspectiva jurídica, así como una herramienta de consulta y análisis para los especialistas del sector.

\section{A. Líneas maestras de la política criminal y el derecho penal de la globalización}

El impacto de la globalización planetaria sobre los distintos fenómenos sociales reviste tal calado que se alude hoy a un nuevo modelo macrosociológico: el de la sociedad de riesgo (Beck, 2002).

El cambio en el potencial de los peligros artificiales en la sociedad actual, básicamente generados por la actividad humana a partir del vertiginoso desarrollo científico-tecnológico, la complejidad organizativa de las relaciones de responsabilidad y la sensación de inseguridad subjetiva - que llega a manifestarse incluso ante situaciones en las que no existen peligros reales- constituyen los caracteres configurativos básicos de este modelo social.

Ciertamente, sobre la actual sociedad global se cierne la amenaza de graves peligros: crisis financieras mundiales, migración fuera de control, contaminación ambiental, niveles preocupantes de desempleo, altos índices de violencia, movilidad social en descenso, terrorismo, crimen organizado, guerras, etc.; todos estos fenómenos, al parecer imposibles de dominar, generan una parálisis en la capacidad de defensa del ser humano y de la sociedad, originándose situaciones de pánico social que traen consigo serias demandadas de control. Se configura así el binomio riesgo-inseguridad en cuya virtud los individuos reclaman al Estado, de manera creciente, la prevención frente al riesgo y la provisión de seguridad (Mendoza, 2001).

La noción básica que se halla en la base del modelo sociológico de la sociedad del riesgo es la aspiración de minimizar la inseguridad y conseguir un control global, aunque esto implique costes para las garantías y los principios sobre los que se monta el sistema penal clásico. La prevención es, bajo este paradigma, la clave para reaccionar ante los problemas de la nueva sociedad configurada a partir de los riesgos.

\section{Política criminal del riesgo}

La comentada problemática ha tenido una marcada influencia sobre la política criminal contemporánea —entendida como la forma en la que se 
debe reaccionar ante el fenómeno delictivo- ${ }^{6}$, cuyos contornos, en congruencia con la línea preventivita apuntada, describen un acentuado adelantamiento de la protección penal a partir de la tipificación de delitos de peligro y la configuración de bienes jurídicos universales de contenido vago. Esto conduce a un derecho penal preventivo --el cual Prittwitz denomina "derecho penal del control global" (como se cita en Mendoza, 2001) - , caracterizado por incrementar el catálogo de bienes jurídicos a partir de la tutela de nuevos intereses, incluso, en un estadio previo a su lesión.

Esta tendencia político-criminal interesada en controlar los riesgos entrega a la nueva sociedad un derecho penal flexibilizado, convertido en un instrumento de la política criminal que, a costa de satisfacer requerimientos de seguridad y eficacia, se aparta de su rol tradicional orientado a la protección de un "mínimo ético" . Esto con el fin de erigirse en instrumento de control de los grandes problemas sociales, con lo cual deja de reprimir puntuales lesiones a bienes jurídicos y de tutelar a víctimas potenciales, y pasa a asumir una proyección preventiva a gran escala de situaciones problemáticas y proteger vagas e indeterminadas funciones, lo que afianza la noción de lo que la

6 La política criminal ha sufrido fuertes impactos en la era de la mundialización, concretamente para responder ante las nuevas exigencias de la llamada "sociedad de riesgo". Como consecuencia de tales matizaciones parece haber adquirido carta de naturaleza el término de política criminal de la era de la globalización o política criminal de la sociedad del riesgo, a la que se asocia un "nuevo" derecho penal, también calificado como "derecho penal del riesgo", el cual contiene la llamada "dogmática de la globalización”. Véanse al respecto Silva (2001) y Mendoza (2001).

7 Sobre la función protectora de bienes jurídicos que ha de cumplir el derecho penal y su relación con el reforzamiento de los valores ético-sociales de la acción, véase Hassemer y Muñoz (1989). doctrina ha calificado como una "huida hacia el derecho penal"s.

Sin embargo, resulta obvio que estas aspiraciones preventivas no pueden alcanzarse bajo el esquema de las clásicas herramientas dogmáticas diseñadas en el seno de un derecho penal nuclear, pensado para reaccionar ante manifestaciones delictivas propias de la sociedad del siglo XIX y de la primera mitad del xx, pues tal modelo, muy por el contrario, impide su materialización ${ }^{9}$. Es por esto que las estructuras básicas del derecho penal tradicional - entiéndase, los clásicos presupuestos de imputación objetivos y subjetivos (Silva, 2001)sufren hoy transformaciones y flexibilizaciones conducentes a su reinterpretación en el nuevo contexto, en detrimento de la efectiva vigencia de los principios y las garantías propios de un sistema penal democrático, de manera que, en consecuencia, también son objeto de una funcionalización a partir de los nuevos intereses político-criminales.

Se advierte así un giro copernicano respecto al tradicional vínculo que, desde la perspectiva de Von Liszt, se establecía entre la política criminal

8 Se alude a la "huida hacia el derecho penal" como expresión sinónima de "fe desmedida en el derecho penal", de "expansionismo penal", de "penalización de los conflictos sociales", de "hipertrofia penal”, etc. El fenómeno que subyace a todas estas expresiones es el de la funcionalización del derecho penal, al que se le concede cada vez más - con olvido de su naturaleza subsidiaria- el primado absoluto frente los instrumentos no penales para reaccionar (y pretender solucionar) problemas sociales que no puede resolver, frente a los cuales se muestra absolutamente inoperante y, más aún, contraproducente. Con lo cual esta rama del ordenamiento jurídico pierde cada vez más su papel de ultima ratio, de extrema ratio, para convertirse en la vía primaria o reacción natural al delito (García-Pablos, 2012; Luzón, 2012).

9 En este sentido apunta Mendoza (2001) que "las crecientes y difusas demandas preventivas de una política criminal interesada en controlar el riesgo no pueden ser satisfechas a través de un derecho penal liberal, que estaría más bien dirigido al pasado, que está dotado de un arsenal de medios limitados y que, como instrumento preventivo, ha de ser prudente" (p. 48). 
y el derecho penal, en el sentido de que este constituía la barrera infranqueable de aquella. En el actual contexto, por el contrario, resulta evidente cómo el derecho penal cede de manera progresiva su papel limitador a fin de complacer las demandas de criminalización formuladas por una política criminal que se desentiende de los principios de necesidad y ultima ratio para convertirse, en palabras de Hassemer (como se cita en Mendoza, 2001) en el "brazo alargado" de aquella.

\section{Derecho penal del riesgo o derecho penal "moderno" (o la Hidra de Lerna)}

Bajo los designios de la política criminal de la sociedad del riesgo, el derecho penal se ha convertido en el destinatario fundamental de las exigencias de seguridad demandadas por la opinión pública para el control de los nuevos peligros. En este sentido, se le atribuye un rol que no le pertenece y, con esto, se generan sensibles fisuras en el modelo garantista clásico $^{10}$.

No existe duda alguna de que el tercer milenio exhibe un derecho penal que se parece cada vez menos a un instrumento de tutela de la libertad, a fin de erigirse paulatinamente en un dinámico

10 Debe tenerse en cuenta que la idea de la inseguridad, interpretada en sus extremos, conduce irremediablemente a la instauración de un "Estado de la seguridad" que supone un cambio de perspectiva para el derecho penal en la medida en que se aleja del tradicional modelo reactivo-represivo y limitador para asumir uno preventivo (Mendoza, 2001). Una caracterización sobre las implicaciones que se derivan de la asunción de este modelo puede verse ya en Baratta (1991). sistema de gestión primaria de los problemas sociales ${ }^{11}$. Esta gran transformación -o irreconocible deformación (Flávio, 2003) - de la que ha sido objeto el derecho penal clásico en la era de la globalización planetaria, convertido en un hipertrofiado producto de comprobada ineficacia ${ }^{12}$, nos sitúa frente a lo que Morales (2015) denomina "nueva

11 Actualmente, existen serios temores y preocupaciones ante la progresiva transformación del derecho penal en un derecho de gestión ordinaria de los grandes problemas sociales, en cuanto esto implica la desnaturalización de esta rama del derecho como ultima ratio del Estado para resolver los conflictos (Feijoo, 2008). Especialmente crítico frente esta situación se ha mostrado Hassemer (1998), quien ha denunciado cómo en estos tiempos el derecho penal se desarrolla con tanta fuerza, homogeneidad y aceptación gracias al clima protector y asistencial imperante, que llega a concebirse como un "instrumento eficaz para afrontar los modernos problemas que van desde las agresiones al medio ambiente a la drogadicción, pasando por el abuso del sistema social. A la vista de los grandes problemas que amenazan la sociedad, en el actual discurso político del derecho penal no vale tendencialmente como ultima, sino como prima o incluso como sola ratio" (p. 38).

12 En este sentido merecen destacarse las palabras de Inzunza (2009) cuando sostiene, con acierto, que "la excesiva confianza en el derecho punitivo como medio para solucionar conflictos sociales no puede menos que calificarse de irracional y de injustificada; irracional, porque desborda las funciones que puede desempeñar, incursionando en un espiral que ensancha sus competencias y agrava la forma de su intervención. No solo existen más tipos penales, sino que las sanciones alcanzan cotas de violencia que en muchos casos llegan a superar la generada hacia la víctima por el autor del hecho criminalizado; injustificada, porque la intervención punitiva no es capaz de lograr los fines que se le atribuyen, sino que, por el contrario, genera un déficit de actuación que deslegitima y pone en entredicho el entero funcionamiento del Estado del que la justicia penal aparece como la cara más visible” (p. 40). 
Edad Media"13, lo cual puede evidenciarse a partir de los caracteres que se presenten a continuación.

\section{Preponderancia de la criminalización, conducente a una hipertrofia irracional}

Si bien los orígenes del excesivo protagonismo del derecho penal no pueden relacionarse con la globalización ${ }^{14}$, sí resulta innegable que en este nuevo contexto socioeconómico y político, de signo neoliberal, la expansión patológica del punitivismo ha alcanzado sectores que antes quedaban libres de la intervención penal ${ }^{15}$.

Más allá de la microcriminalidad propia de las clases marginales (crimes of the powerless), sobre la que el derecho penal desde hace algún tiempo centraba su atención a partir de las campañas de "ley y orden", ahora también se aprecia un aumento

13 Morales (2015) ofrece una caracterización detallada de la situación que enfrenta hoy el derecho penal, y deja constancia de cómo se ha materializado la hipertrofia de esta rama del ordenamiento jurídico. Sostiene que "en la nueva Edad Media el penalista se interroga por si las garantías del derecho penal, que han dotado de identidad al modelo de justicia, están en jaque o han empezado a sufrir un declive inexorable, que puede conducir a un nuevo período de anarquía punitiva como el que presidió el mundo anterior al pensamiento de la Ilustración. Estado-nación, legalidad y seguridad jurídica son conceptos y valores que no cotizan al alza en la nueva Edad Media” (p. 24).

14 Merece aclararse que, en realidad, los actuales caracteres que distinguen el llamado "derecho penal de la 'modernidad" no tienen su origen exclusivo en el proceso globalizador, por lo que lleva razón Flávio (2003) cuando aclara: "El derecho penal en la era de la globalización es el reflejo de todas las transformaciones (del derecho penal tradicional) que fueron sucediendo a lo largo de los dos últimos siglos (XIX y Xx), particularmente después de la Segunda Guerra Mundial, más las profundas y nuevas alteraciones inherentes a la propia globalización" (p. 338).

15 Al respecto sostienen Arroyo, Neumann y Nieto (2003): "El suelo penal se ha extendido a nuevas y numerosas zonas tradicionalmente libres de derecho penal"; además, califican la delincuencia económica como "el ejemplo más evidente y de mayor dimensión” (p. 19). del interés general por la criminalización de conductas lesivas protagonizadas por los poderosos, fundamentalmente las de naturaleza económica (crimes of the powerfull) $)^{16}$.

\section{Frecuentes y parciales alteraciones de la parte especial de los códigos penales y edición de leyes penales especiales, cual expresión de la función simbólica que desempeña hoy el derecho penal}

La sucesivas, incoherentes y asistemáticas reformas que se implementan respecto a las construcciones típicas de las distintas figuras que conforman el catálogo de la parte especial de los códigos penales, así como la frecuente aparición de leyes penales especiales, constituyen auténticas expresiones del simbolismo, la instrumentalización y el expansionismo que aquejan al derecho penal en la actualidad.

Ante los grandes problemas inherentes a la sociedad globalizada — como, por ejemplo, la seguridad ciudadana y el crimen organizado, por citar solo dos ejemplos-, se nota cómo los poderes públicos acuden continuamente al derecho penal, a través de las permanentes reformas, a fin de transmitir a la ciudadanía una opción política cuyo contenido se traduce en un mensaje de solidaridad con sus preocupaciones. De este modo, asumen una función política, de legitimación y dirección

16 Según Flávio (2003) “en el pasado tenían protagonismo exclusivamente las reivindicaciones político-criminales típicas del movimiento de la ley y del orden (criminalización de los marginados y de la micro-criminalidad; encarcelamiento masivo de los excluidos; 'tolerancia cero', etc.); en la actualidad, en la era de la globalización, ese escenario se ha modificado notablemente: la influencia de la prensa en la justicia es enorme; las reivindicaciones de algunos sectores de la izquierda en contra los poderosos es constante. Luego, la macro-criminalidad también ganó visibilidad ('noticias de primera página'); la reacción social contra esa criminalidad ya es claramente perceptible en esta era de la globalización” (p. 339). 
de las conciencias de los ciudadanos propia de la ética o la moral ${ }^{17}$.

No se alude aquí, obviamente, a las reformas que encuentran plena legitimación y justificación en el fin primordial de tutela de bienes jurídicos y control del delito (función instrumental o material), las que por esencia lleven implícitas innegables dosis de simbolismo positivo ${ }^{18}$; sino a aquellas que, guiadas por la obtención de efectos opuestos a la mencionada finalidad, entrañan,

una instrumentalización del derecho penal en su utilización como medio pedagógico para

17 Sobre esta tendencia político-criminal que orienta al derecho penal en los tiempos de la globalización, resultan magistrales las reflexiones del profesor Borja (2001) cuando apunta que, en estos casos, se produce "una instrumentalización del derecho penal en su utilización como medio pedagógico para tranquilizar a la ciudadanía, para inspirar la suficiente confianza en el sentido de demostrar que los gobernantes políticos y los representantes del pueblo se preocupan por los problemas de la inseguridad ciudadana" (p. 109).

18 Se coincide con Díez (2013b) cuando sostiene la improcedencia de pretender proscribir los efectos simbólicos del derecho penal. Este autor reflexiona sobre la necesaria complementariedad que normalmente se produce entre los efectos instrumentales y simbólicos de toda medida de intervención social, en el entendido de que la modificación de la realidad social lograda a través de la correspondiente medida implica, a su vez, la producción de ciertas representaciones valorativas en los sujetos sobre quienes de un modo directo o indirecto incide aquella. Así, centrándose en el caso del derecho penal, entiende que: "El efecto instrumental que se procura es la evitación de lesiones o puestas en peligro de los bienes fundamentales para la convivencia, en último término la evitación de la delincuencia, y el mecanismo utilizado para su consecución es la promulgación de normas cuya infracción, debidamente comprobada, da lugar a una sanción. Pero en el logro de tal efecto instrumental desempeñan un papel especialmente relevante los efectos psicológicos, esto es simbólicos, que la amenaza de tal sanción o la mera existencia de la norma producen en ciudadanos que pueden considerarse en muy diversa medida delincuentes potenciales” (p. 36). tranquilizar a la ciudadanía, para inspirar la suficiente confianza en el sentido de demostrar que los gobernantes políticos y los representantes del pueblo se preocupan por los problemas de la inseguridad ciudadana (Borja, 2001, p. 109).

Sin embargo, a fin de analizar en qué casos procede hablar de verdadera expansión punitiva, conviene tener presentes las importantes clarificaciones que trae a debate Terradillos (2004). Este autor distingue entre una función simbólica propiamente dicha, la cual entraña siempre la utilización del derecho penal "no tanto para proteger bienes jurídicos como para afirmar valores, confirmar expectativas, generar representaciones valorativas, etc." (p. 235), y en la que se aprecia una supeditación de la función instrumental o material a la función asignada a los símbolos, y lo que él denomina una función enmascaradora, la cual supone un estado de indiferencia por parte del Estado ante delitos que no le interesa perseguir, al tiempo que a través del derecho penal se proyecta una "apariencia de resolución de conflictos que permanecen intocados" (2004, p. 235). De este modo, no se articulan medios para alcanzar los objetivos que supuestamente justifican la intervención penal $y$, por ende, hay que coincidir con Terradillos (2004) cuando sostiene que en tales casos, más que expansión, lo que se aprecia es una inhibición del sistema penal que termina convirtiéndose en cómplice del delincuente al que solo retóricamente dice perseguir.

Algunos de los "beneficios" que granjea esta deslegitimadora opción político-criminal son resaltados por Díez (2013), quien sostiene que la aludida instrumentalización del derecho penal coadyuva al mantenimiento de una imagen positiva y dinámica del legislador, así como de los poderes públicos en sentido general, al tiempo que enmascara la ausencia de otras medidas en materia de intervención social que resulten verdaderamente eficaces ${ }^{19}$.

19 En idéntico sentido lo concibe Terradillos (2004), quien entiende que "a una tipificación inadecuada suele acompañar la ausencia de otras políticas sociales o de prevención más costosas” (p. 236). 
Por otra parte, la aparición de específicas leyes penales que se encargan de regular, extra codicem, específicas manifestaciones de la delincuencia socioeconómica también constituye una manifestación de la analizada tendencia expansiva que asume de manera progresiva el derecho penal ${ }^{20}$. Así, bajo el argumento de la especialidad de la materia objeto de regulación - especialmente vinculada a la normativa extrapenal que le sirve de base-, en la mayoría de los casos estas leyes sectoriales regulan conjuntamente infracciones penales y administrativas, lo cual conduce a la flexibilización o desdibujamiento (cuando no olvido) de los principios y garantías materiales y procesales que rigen el sistema penal ${ }^{21}$. De esta manera, pasa por alto que si bien el sector de la delincuencia económica presenta peculiaridades técnicas, esto no justifica en ningún caso que el enfoque con el cual deba analizarse este tipo de delitos sea el empleado por el derecho administrativo, pues a pesar de que este sector del ordenamiento jurídico y el derecho penal confluyan sobre una misma realidad social,

20 Sobre las distintas opiniones en torno a la polémica código penal/ley penal especial, especialmente en materia de delitos socioeconómicos (Martínez-Buján, 2014, pp. 147-152).

21 Así, Terradillos (2003), quien en punto a la problemática relacionada con aquel sector del derecho penal regulado en leyes penales especiales (al que él denomina "derecho penal de 'segundo nivel"') sostiene que "excepcionaría, sobre todo en los aspectos garantizadores, a la parte general del Código Penal”; ejemplifica esta problemática a partir de las relaciones entre el principio de lesividad y la construcción de los delitos de peligro, cuyo esquema se muestra más flexibilizado en este tipo de normas administrativas o económicas en las que el fundamento de aquellas tipologías delictivas se hace descansar, la mayoría de las veces, en el mero refuerzo de decisiones administrativas, o se basan en presunciones; contraviniendo así los criterios de necesidad y proporcionalidad que deben observarse al momento de la incriminación penal (pp. 514 y 526). la autonomía del derecho penal supone una perspectiva de análisis propia y diferente ${ }^{22}$.

El abuso de la legislación penal especial, además de favorecer la elusión de las exigencias principiales más estrictas de los códigos, también comporta una importante pérdida de seguridad jurídica y suele ir acompañada de un significativo descenso de la calidad técnica de la ley penal ${ }^{23}$.

Tal problemática no escapa al ámbito cultural iberoamericano, en el que, a pesar del arraigo del principio de codificación, se advierte la proliferación de leyes penales especiales en un buen número de países, entre los que cabe mencionar a Argentina, Brasil, Chile, Ecuador y Venezuela ${ }^{24}$.

\section{La protección funcional de bienes jurídicos, excesiva creación de delitos de peligro abstracto y crisis del principio de lesividad $u$ ofensividad}

Con el advenimiento de la globalización ha proliferado una marcada tendencia a dirigir la tutela penal

22 Al respecto argumenta Terradillos (2003) que, "sin marginar las exigencias impuestas por la complejidad y especialización propias de las materias objeto de regulación, el derecho penal puede reservarse un campo de definición autónomo”; extremo que, al decir de este autor, “resultará más idóneo de cara a sus objetivos (preventivos), que no son los de la legislación sectorial (regulativos, promocionales, de inspección y control, etc.)” (p. 517).

23 El principio de codificación proclama, en esencia, la necesidad de que la materia penal aparezca regulada en cuerpos legales omnicomprensivos (códigos penales y procedimentales), cuyo fundamento descansa en la idea de seguridad jurídica y respeto a los principios y garantías básicos del derecho penal; y al decir de Díez (2013a), esta opción "supone un esfuerzo de racionalización del sistema de control penal, y de obstaculización de decisiones legislativas proclives a abandonar los principios fundamentales del derecho penal por razones coyunturales".

24 En la región latinoamericana esta tendencia se concentra mayoritariamente en contenidos de la Parte Especial, en tanto dichos cuerpos normativos bien introducen nuevos delitos no presentes en el código, o bien excluyen de aquellos determinados delitos al formularlos de otra manera. 
hacia bienes jurídicos supraindividuales (universales, colectivos, difusos), los cuales ostentan una configuración vaga e imprecisa y en los que no se reconoce, al menos en la mayoría de los casos, un referente directo a un interés individual. Se evidencia así la crisis en que se halla sumido el principio de la protección de bienes jurídicos ${ }^{25}$, cada vez más distanciado de su originaria función de límite negativo de la criminalización para asumir un moderno rol justificativo de la intervención penal.

A tono con la emergencia de bienes jurídicos supraindividuales se advierte un reiterado empleo de la técnica legislativa consistente en la configuración de delitos de peligro abstracto, construidos muchas veces sobre la base de la mera desobediencia a la norma, con lo cual se menosprecia el contenido material del principio de lesividad. Se difuminan, por tanto, las fronteras que delimitan lo penalmente relevante del mero ilícito administrativo, sin que pueda soslayarse además que tales incriminaciones revisten enormes dificultades de cara al ejercicio del derecho de defensa y, en oposición, se favorece la actividad persecutoria del Estado ${ }^{26}$.

\section{Flexibilización del mandato de taxatividad, ínsito al principio de legalidad penal}

Con más frecuencia de la deseada se acude a la técnica legislativa de normas penales en blanco, en las

25 Un derecho penal democrático solo deberá amparar como bienes jurídicos condiciones de la vida social, singularmente importantes, en la medida en que afecten las posibilidades de participación del individuo en el sistema social; de modo que no deben respaldarse mandatos puramente formales, ni valores puramente morales, ni intereses no fundamentales que no comprometan seriamente el funcionamiento del sistema social (Mir, 2011, pp. 129-130).

26 Según Hassemer (2009), con el empleo de la técnica de los delitos de peligro abstracto "el legislador alivia el trabajo del juez a la hora de la determinación de los hechos relevantes desde la perspectiva típica; y agrava, al mismo tiempo, el trabajo de la defensa penal, cuya tarea se reduce al número específico de los presupuestos de la punibilidad" (p. 16). que se aprecia una erosión del contenido de injusto en la medida en que los límites de la norma de conducta se desplazan hacia difusos sectores normativos de la administración pública. Con esto se concede a las instancias administrativas funciones directamente relacionadas con la determinación de lo penalmente relevante cuando esto, legal y constitucionalmente, constituye una función que compete en régimen de exclusividad al legislador.

\section{Protagonismo de la función intimidatoria del derecho penal en desmedro de los principios de igualdad y proporcionalidad}

Bajo el ideal del Estado preventivo o Estado de la seguridad, la principal aspiración del derecho penal moderno se dirige a prevenir futuras perturbaciones, más allá de la idea de seguridad o certeza; de modo que ya no importa tanto retribuir proporcionalmente el mal causado, sino más bien alcanzar la confianza de todos los ciudadanos en la inviolabilidad del orden jurídico penal (Hassemer, 2009).

Sobre los costes que implica la asunción de este modelo reflexiona Hassemer (2009, p. 39) —vinculando el principio general de proporcionalidad con el principio de culpabilidad- en el sentido de que,

este principio (el de culpabilidad) aparece especialmente amenazado en un sistema penal que persigue objetivos preventivos y que por tanto está particularmente interesado en alcanzar consecuencias beneficiosas mediante presión y golpes de efecto —no solo entre los afectados sino también ante la opinión pública conformada por los medios-.

\section{Transformación funcionalista de categorías dogmáticas clásicas}

En el seno del derecho penal moderno, enfocado hacia la prevención y el control de los nuevos riesgos, se plantean problemas a los que los clásicos 
contenidos de las viejas categorías dogmáticas parecen no ofrecer una respuesta adecuada ${ }^{27}$.

Como quiera que la configuración tradicional de aquellas se erige en obstáculo para la eficacia de la nueva política criminal, se generan propuestas de interpretación que provocan disfunciones respecto a las clásicas estructuras y reglas de atribución de la responsabilidad penal, en especial las vinculadas al entendimiento de la relación de causalidad, al contenido del dolo y la imprudencia, a la delimitación entre autoría y participación, así como a las fronteras entre la consumación y las formas de realización imperfecta del tipo (Hassemer, 1992).

El derecho penal de nuestros días muestra un panorama ensombrecido que implica un preocupante distanciamiento de las bases del Estado de derecho y, correlativamente, un acercamiento al totalitarismo (González, 2007; Morales, 2015).

\section{B. Pautas básicas para una modernización razonable del derecho penal}

No es posible dudar que vivimos en una sociedad diferente - ya se le denominó "sociedad del riesgo", "sociedad del peligro", "sociedad postindustrial", etc.-, la cual se distancia notablemente del modelo de sociedad preindustrial centrada en la protección de bienes de carácter individual. Además, es distinta también de la sociedad industrial decimonónica que vio nacer los valores de solidaridad, confianza social e intereses colectivos. Son tiempos de globalización neoliberal, con todos sus "atributos".

Los múltiples peligros e inseguridades de carácter colectivo, sobredimensionados en sus contornos gracias a la opinión pública, generan demandas de criminalización apoyadas en

27 Sobre este particular apunta Mendoza (2001): "Las crecientes y difusas demandas preventivas de una política criminal interesada en controlar el riesgo no pueden ser satisfechas a través de un derecho penal liberal, que estaría más bien dirigido al pasado, que está dotado de un arsenal de medios limitados y que, como instrumento preventivo, ha de ser prudente” (p. 48). necesidades de defensa ante peligros que la mayoría de las veces solo están definidos por criterios estadísticos. A esto responden los poderes públicos creando tantas figuras delictivas como sea posible para proteger a la sociedad de los riesgos anunciados (Bajo, 2013), de tal suerte que se configura a este compás un derecho penal inflacionado, irrespetuoso con los derechos y garantías fundamentales $\mathrm{y}$, por demás, carente de efectividad y eficacia (Mendoza, 2001).

Esta situación ha conllevado a que en la actualidad el modelo teórico del derecho penal atraviese una evidente situación de crisis. Las manifestaciones de ese modernizado instrumento punitivo, fundamentadas en un discurso proeficacia de contornos ilimitados, constituyen una amenaza cierta de destrucción para el conjunto de garantías que han sustentado el sistema clásico de imputación penal, con el que conectan los principios político-criminales (Silva, 2001) ${ }^{28}$.

Se trata de la cristalización del derecho penal del enemigo (Sanz, 2012), epidemia jurídica que arrasa con la idea del imperio de la ley ${ }^{29}$, con las exigencias básicas del Estado de derecho y con la legitimidad democrática (Maresca, 2005); además, se expande de forma incontenible como consecuencia del

28 En este sentido alerta Mendoza (2001) en punto a que “...con el propósito de conseguir una mayor eficacia de la protección penal se puede estar configurando un modelo que, sin lograr la eficacia que persigue, pretendidamente apoyada en razones de legitimación utilitaria, abandone aquellas garantías que le otorgan justificación axiológica” (p. 182).

29 En opinión de Maresca (2005) “...en la cultura del Estado de Derecho la idea del imperio de la ley está unida a la de poner límites al poder del Estado, y concretamente a la idea de minimizar el poder punitivo del Estado” (p. 88). 
fenómeno de la internacionalización ${ }^{30}$. Los Estados nacionales, en una mezcla de impotencia y servilismo frente a las decisiones de organismos globales, permiten que sus ordenamientos jurídicos resulten inoculados por las más peligrosas manifestaciones del expansionismo irracional.

No obstante, pese a que la situación actual se nos presente con altísimas dosis de complejidad, es necesario coincidir con Zúñiga (2001) cuando, refiriéndose a las características de ese nuevo derecho penal, defiende que no pueden entenderse como inevitables y menos aún como valorativamente legítimas.

Se impone así la búsqueda de una solución. Desde la perspectiva que aquí se defiende, el presupuesto es admitir la necesaria modernización del derecho penal clásico, puesto que defender su utilidad en el contexto de la sociedad actual sería algo más que una utopía. Sin embargo, habrá que rehuir de aquella tendencia que, orientada hacia el discurso de la eficacia ${ }^{31}$, propugna el empleo del derecho penal como instrumento de pedagogía social, de transformación de las estructuras sociales, como gestor de grandes conflictos que en realidad solo encontrarían una solución adecuada en otras instancias de protección distintas al sistema penal.

Es cierto que el sistema penal tradicional está pensado para otras épocas y circunstancias, y que, por tanto, se muestra insuficiente en el propósito

30 La internacionalización del derecho penal es otra de las consecuencias de la globalización. Su principal significado es que el derecho deja de ser la realidad estática de un determinado ordenamiento para convertirse más en un proceso dinámico de intercambio entre los distintos órdenes de intereses, a tal punto que se va gestando una especie de modelo global al que debe responder toda la actividad incriminadora desarrollada por los Estados para hacer frente a ciertas manifestaciones delictivas, normalmente asociadas a la criminalidad organizada. Sobre las notas características de este fenómeno y su influencia en el derecho penal contemporáneo, entre otros, véanse Méndez (2005), Vogel (2008) y Berdugo (2012).

31 En este sentido alerta Corcoy (2012) que "la eficacia, siendo necesaria, no puede ser el único criterio si no se quiere terminar en un Estado policial” (p. 154). de controlar las formas de criminalidad impulsadas por la economía globalizada. Esto en razón a que sus manifestaciones responden a un modelo de sociedad de corte posindustrial que necesita de un derecho penal preparado y dispuesto a controlar conductas que agredan derechos colectivos, que vayan más allá de los derechos subjetivos para los que están pensados los actuales sistemas penales; esto es, un derecho penal que le sirva de cortapisas a una economía global que no respeta principios ni fronteras. No obstante, todo lo anterior tampoco puede interpretarse como más control penal o más represión.

Solo una modernización del derecho penal que se lleve a cabo con escrupuloso respeto por las garantías ínsitas al Estado de derecho y no a golpes de seguridad representará una verdadera evolución de este (Sanz, 2012). Esto implica que el proceso globalizador ha de ser sometido a un control democrático, en busca de nuevas reglas que eviten sus efectos perjudiciales, pero retomando en todo caso el discurso garantista y el debate sobre los valores.

Por tanto, la clave no parece hallarse en las propuestas extremas que optan por un expansionismo irracional, ni en una injustificada inhibición de la intervención punitiva frente a sectores necesitados y merecedores de tutela penal, sino en una posición intermedia que, desde una perspectiva más coherente, se muestra a favor de una expansión razonable del derecho penal -en la medida en que así lo exigen los cambios sociales- a aquellos ámbitos que verdaderamente requieran y merezcan protección por parte de esta rama del ordenamiento 
jurídico ${ }^{32}$, pero siempre con sujeción a los límites que al ejercicio del poder punitivo imponen los principios sobre los que se erige el derecho penal de un Estado de derecho ${ }^{33}$.

Ubicar el derecho penal en una posición en la que compatibilicen su acomodo a las exigencias de la contemporaneidad y el respeto al sistema de garantías básicas supone, ante todo, fomentar en primera opción el recurso a otras vías de regulación distintas a la penal, de tal suerte que se emplee esta última con el carácter excepcional que se le debe asignar (Mendoza, 2001). La asunción real (y no meramente formal) del carácter subsidiario y de ultima ratio del derecho penal en la solución de los conflictos sociales conduciría a un derecho penal más pequeño que, precisamente por esto, sería un instrumento más eficaz (Ferré, 2007).

Lo anterior exige el rescate y la potenciación de los roles legítimos de otras instancias de control, porque solo así quedarán aseguradas la seriedad y la eficacia de la conminación penal sin que

32 Al respecto, sostiene con agudeza Sanz (2012) que "no se trata de abogar por una retirada drástica del derecho penal, sino de que preste batalla allí donde puede, y sin renunciar a las tradicionales reglas de imputación y a los principios garantistas que ordena dicha actuación” (pp. 141-142). Desde una perspectiva centrada en la necesidad y la racionalidad de la intervención penal ante los nuevos intereses dignos y necesitados de tutela, Terradillos (2004) se muestra igualmente partidario de la tutela penal frente a ciertos ámbitos, como lo es el de la responsabilidad por el producto, que entraña un riesgo para la vida o la integridad física de los consumidores incluso con una dimensión transnacional.

33 Según Mendoza (2001), se trata de "no forzar al derecho penal en una tarea de prima ratio, ni de pedagogía social, ni de satisfacción de necesidades -en parte objetivas y en buena medida subjetivas - de seguridad y prevención, que no es seguro que consigan lo que se proponen, pero que con certeza están suponiendo, en más casos que los deseables, transformaciones o tendencias no conciliables con el sistema basado en categorías dogmáticas racionales y coherentes, y en principio garantistas de ineludible cumplimiento en el derecho penal de un Estado de derecho avanzado” (pp.188-189). en ningún caso pueda renunciarse a ello por más problemas estructurales y operativos que se atribuyan a otras ramas o sectores del ordenamiento jurídico ${ }^{34}$. Se trata, en última instancia, de llevar a cabo un adecuado proceso de selectividad sobre lo penalmente relevante que, además de realzar la vigencia cada vez más relegada del principio de intervención mínima, apueste por la recuperación del rol crítico de la teoría del bien jurídico en aras de enfrentar la apocalíptica tendencia expansiva (Pariona, 2007) $)^{35}$.

Así, la legitimidad de la intervención punitiva deberá evaluarse no por su repercusión en un determinado sector de la vida social, sino por el grado de respeto a los principios de atribución de responsabilidad individual en cada caso, esto es, analizando la legitimidad de la norma en concreto (Sanz, 2012). Esto implica —más allá de los desaciertos que puedan signar la técnica legislativa empleada en cada caso, siempre perfectible-, que el proceso de interpretación desarrollado por los sujetos procesales con capacidad decisoria no esté

34 Así, lleva razón Mendoza (2001) cuando sostiene que "propugnar que jueguen el debido papel el derecho civil, el administrativo sancionador convenientemente reformado y adaptado-y el derecho mercantil, no supone dejar de reconocer las insuficiencias que puedan atribuirse a estos, ni olvidar su posible inoperancia o la menor exigencia de garantías que puedan darse trasladando el problema a otras ramas del ordenamiento jurídico. Pero tampoco puede suceder, a la inversa, que estos defectos agudicen la tendencia a recurrir a la más radical 'solución penal', sobrecargando al derecho penal, operando transformaciones que desnaturalicen, en suma, el carácter del recurso a la pena criminal” (p. 187).

35 En igual sentido lo plantea Corcoy (2012), quien apuesta por un rescate necesario de los límites derivados de los principios de ultima ratio, fragmentariedad y lesividad. Así, entiende esta autora que "muchas veces la pregunta no es tanto si se debe castigar una determinada conducta en atención a lo que se pretende evitar, sino cómo se debe castigar; es decir, preguntarse qué conductas de entre todas las posibles son realmente lesivas y limitar la intervención penal en este sentido" (p. 160). 
regido por exclusivos criterios literales o gramaticales, sino que dé cabida a los teleológicos (los cuales tomen en cuenta la referencia al bien jurídico) y los sistemáticos (a partir de la necesaria comparación entre figuras delictivas afines y de la normativa extrapenal) (Corcoy, 2012).

Cierto es que la postura aquí defendida entraña conocidas dificultades, pero también es verdad que uno de los fines más relevantes del Estado democrático consiste en lograr un equilibrio entre la garantía de una vigencia razonable de los derechos fundamentales y de las libertades públicas, y una eficaz tutela de los bienes jurídicos más esenciales a fin de mantener una digna convivencia social $\left(\right.$ Borja, 2012) ${ }^{36}$.

Se es consciente de que el reacomodo del derecho penal a las nuevas realidades dependerá, en buena medida, de la evolución de la economía y de la sensibilidad social de los agentes políticos y económicos que hoy dominan el mundo. Sin embargo, también, como ha destacado Muñoz (2004), del nivel de resistencia intelectual que podamos oponer los penalistas y criminólogos comprometidos con la prevención de la criminalidad en el marco de las coordenadas del Estado de derecho.

Esta posición teórica, que tiene en Günther Jakobs a uno de sus principales ideólogos, representa sin duda una amenaza para las concepciones democráticas que se hallan en la base del Estado de derecho en tanto sirve de coartada

36 En idéntico sentido lo concibe De la Cruz (2014), quien entiende cómo "hay que procurar alcanzar un punto de equilibrio entre el patrón empírico de 'eficacia' y el patrón valorativo de 'garantías', es decir, entre el derecho penal como manifestación de la pretensión punitiva del Estado en pro de la convivencia social y la reglamentación garantística de un debido proceso que resguarde la dignidad humana" (p. 84). En congruencia con esto, Medina (2016) sugiere que se diseñe una política criminal "en la que se logre la necesaria armonía entre la necesidad de adaptar las normas penales y de procedimiento al surgimiento de nuevos intereses de protección o la revalorización de algunos ya existentes y la necesidad de garantizar la vigencia de un proceso penal garantista y respetuoso de los derechos fundamentales, frente a la innegable criminalidad de nuevo “corte”' (p. 348). ideológico-penal a las comentadas iniciativas legislativas (Ramos, 2004).

\section{Conclusión}

Cabe afirmar, en términos conclusivos, que un derecho penal ajustado a nuestros tiempos - el que necesitamos para hacer frente a los fenómenos inherentes a la contemporaneidad globalizada - tendrá que ser un derecho penal que se adapte a los nuevos perfiles del fenómeno criminal: la cultura de la violencia, de la criminalidad económica organizada y del terrorismo internacional (Sanz, 2011). Sin embargo, conviene no perder de vista que los estándares de eficacia que esta rama del orden jurídico puede y debe cumplir solo resultan alcanzables, en el contexto de un modelo democrático, siempre que se preserven las comentadas conquistas garantistas. La clave está, como ha resumido magistralmente Sanz (2012), en hacer frente a los "nuevos" problemas sin olvidar los "viejos" límites, pues lo contario supone el desvanecimiento de un derecho penal democrático y, correlativamente, la emergencia de un derecho penal totalitario que parece tener un recobrado ímpetu y una renovada reformulación teórica (Carbonell, 2016; González, 2016).

\section{Referencias}

Arroyo, L., Neumann, U. y Nieto, A. (Coords.). (2003). Crítica y justificación del derecho penal en el cambio de siglo. El análisis crítico de la Escuela de Frankfurt. Cuenca, España: Ediciones de la Universidad de Castilla-La Mancha.

Bajo, M. (2013). Los delitos económicos como manifestación característica de la expansión del derecho penal. En F. Álvarez, M. Cobos, P. Gómez, A. Manjón-Cabeza, y A. Martínez (coords.), Libro homenaje al prof. Luis Rodríguez Ramos (pp. 407-416). Valencia: Editorial Tirant lo Blanch.

Baratta, A. (1991). Funciones instrumentales y simbólicas del derecho penal: una discusión en la perspectiva de la criminología crítica. Pena y Estado (función simbólica de la pena), 1, 37-55.

Beck, U. (1998). ¿Qué es la globalización? Falacias del globalismo, respuestas a la globalización. Barcelona: Editorial Paidós.

. (2002). La sociedad del riesgo global. Madrid: Siglo xxi de España Editores. 
Berdugo, I. (2012). Acerca de la internacionalización del derecho penal. En A. Pérez (dir.), El principio de justicia universal. Fundamento y límites (pp. 21-44). Valencia: Editorial Tirant lo Blanch.

Blanco, I. (2012). El delito de blanqueo de capitales. Navarra: Editorial Aranzadi.

Borja, E. (2001). Curso de política criminal. Valencia: Editorial Tirant lo Blanch.

_-__- (2012). Custodia de seguridad, peligrosidad postcondena y libertad en el Estado democrático de la era de la globalización: una cuestión de límites. Revista General de Derecho Penal, 18, 1-57.

Carbonell, J. (2016). Las garantías democráticas en tiempos de cambio: legalidad y culpabilidad. En A. Medina, El derecho penal en tiempos de cambios. Libro homenaje al profesor Luis Fernando Niño (pp. 121-134). La Habana: Editorial Unijuris.

Corcoy, M. (2012). Crisis de las garantías constitucionales a partir de las reformas penales y de su interpretación por los tribunales. En S. Mir, M. Corcoy, y J. Hortal (coords.), Constitución y sistema penal (pp. 153-174). Madrid: Editorial Marcial Pons.

Correcher, J. (2013). Evolución del derecho penal supraestatal: pluralismo y garantismo jurídico como criterios orientadores. Cuadernos Electrónicos de Filosofía del Derecho, 28, 109-128. Recuperado de http://roderic. uv.es/handle/10550/32440

Cruz, R. de la. (2014). La polémica actual en el derecho penal. En A. Medina, El derecho penal de los inicios del siglo XXI en la encrucijada entre las garantías penales y el expansionismo irracional (pp. 10-10). La Habana: Editorial Unijuris.

Díez, J. (2013a). Exigencias sociales y política criminal. En J. Díez, Política criminal y derecho penal. estudios (pp. 33-44). Valencia, España: Editorial Tirant lo Blanch.

____- (2013b). La política legislativa penal iberoamericana a principios del siglo xxi. En J. Díez, Política criminal y derecho penal. Estudios (pp. 267-301). Valencia, España: Editorial Tirant lo Blanch.

Feijoo, B. (2008). Política criminal y delitos socioeconómicos. En J. Boix (dir.), Diccionario de derecho penal económico (pp. 680-688). Madrid: Editorial Iustel.

Ferré, J. (2007). ¿Hacia un derecho penal sectorializado? En F. Pérez, M. Núñez, e I. García (coords.), Universitas vitae: homenaje a Ruperto Núñez Barbero (pp. 229-244). Salamanca: Editorial de la Universidad de Salamanca.

Flávio, L. (2003). Globalización y derecho penal. En J. Díez, C. Romeo, L. Gracia, y J. Higuera (eds.), La ciencia del derecho penal ante el nuevo siglo. Libro homena- je al profesor doctor don José Cerezo Mir (pp. 331-348). Madrid: Editorial Tecnos.

García-Pablos, A. (2012). Introducción al derecho penal. Instituciones, fundamentos y tendencias del derecho penal (vol. 2). Madrid: Editorial Centro de Estudios Ramón Areces.

González, J. (2016). El renacimiento del derecho penal totalitario: la doctrina del derecho penal del enemigo. En A. Medina, El derecho penal en tiempos de cambios. Libro homenaje al profesor Luis Fernando Niño (pp. 135155). La Habana: Editorial Unijuris.

Hassemer, W. y Muñoz, F. (1989). Introducción a la criminología y al derecho penal. Valencia: Editorial Tirant lo Blanch.

_-__.. (1992). Rasgos y crisis del derecho penal moderno. Anuario de Derecho Penal y Ciencias Penales, 45(1), 235-250.

_-_-_. (1998). Perspectivas del derecho penal futuro. Revista Penal, 1, 37-41.

(2009). El derecho penal en los tiempos de las modernas formas de criminalidad. En H. Albrecht, U. Sieber, J. Simón, y F. Schwarz (comps.), Criminalidad, evolución del derecho penal y crítica al derecho penal en la actualidad (pp. 15-28). Buenos Aires: Ediciones del Puerto.

Inzunza, E. (2009). La exacta aplicación de la ley penal y el mandato de determinación. México D. F.: Instituto de Investigaciones Jurídicas de la Universidad Nacional Autónoma de México.

Luzón, D. (2012). Lecciones de derecho penal. Parte General. Valencia: Editorial Tirant lo Blanch.

Martínez, A. (2005). Economía de la globalización. Anuario de la Facultad de Derecho de la Universidad Autónoma de Madrid, 9, 17-39.

Maresca, M. (2005). Antes de Leviatán. Las formas políticas y la vida social en la crisis del imperio de la ley. En G. Portilla (coord.), Mutaciones de Leviatán. Legitimación de los nuevos modelos penales (pp. 87-118). Madrid: Editorial Akal.

Martínez-Buján, C. (2014). Derecho penal económico y de la empresa. Parte general. Valencia: Editorial Tirant lo Blanch.

Medina, A. (2016). Globalización, violencia e inseguridad ciudadana en tiempos de transformaciones del derecho penal. En A. Medina, El derecho penal en tiempos de cambios. Libro homenaje al profesor Luis Fernando Niño (pp. 347-375). La Habana: Editorial Unijuris.

Méndez, C. (2005). Hacia la internacionalización del derecho penal. En I. Berdugo, y N. Sanz (coords.), Derecho 
penal de la democracia vs seguridad pública (pp. 3364). Granada: Editorial Comares.

Mendoza, B. (2001). El derecho penal en la sociedad del riesgo. Madrid, España: Editorial Civitas.

Mir, S. (2011). Derecho penal. Parte General. Barcelona: Editorial Reppertor.

Morales, F. (2015). La utopía garantista del derecho penal en la nueva "Edad Media". Barcelona: Ediciones Gráficas Rey.

Muñoz, F. (2004). El nuevo derecho penal autoritario. En M. Losano, y F. Muñoz (coords.), El derecho ante la globalización y el terrorismo. Actas del Coloquio Internacional Humboldt, Montevideo abril 2003 (pp. 161-184). Valencia: Editorial Tirant lo Blanch.

Pariona, R. (2007). El derecho penal “moderno". Revista Penal, 20, 155-166.

Ramonet, I. (2000). Situación actual del proceso de globalización. En El proceso de globalización mundial. Hacia la ciudadanía global. Barcelona: Editorial Intermon Oxfam.

Ramos, J. (2004). Símbolos y enemigos: algunas reflexiones acerca de la nueva lucha antiterrorista. En F. Pérez (Ed.), Serta. In memoriam Alexandri Baratta (pp. 1425-1446). Salamanca: Ediciones Universidad de Salamanca.

Sanz, N. (2011). El derecho penal del enemigo y la obstinación de justificar lo injustificable. En F. Muñoz, J. Lorenzo, J. Ferré, E. Cortés, y M. Núñez (dirs.), Un derecho penal comprometido. Libro homenaje al prof.
Dr. Gerardo Landrove Díaz (pp. 1029-1070). Valencia: Editorial Tirant lo Blanch.

_-_- (2012). El derecho penal ante los retos del siglo Xxi: la urgencia de un derecho penal que haga frente a los "nuevos problemas", pero sin olvidar los "viejos límites”. Cuadernos de Política Criminal, 106(I), 115-151. . (2016). Política criminal (actualizado a las reformas de 2015). Salamanca: Editorial Ratio Legis.

Silva, J. (2001). La expansión del derecho penal. Aspectos de la politica criminal en las sociedades postindustriales. Madrid: Civitas Edicione.

Terradillos, J. (2003). Código penal-leyes penales especiales. Diez cuestiones sobre una tensión no resuelta. En J. Díez, C. Romeo, L. Gracia, y J. Higuera (edits.), La ciencia del derecho penal ante el nuevo siglo. Libro Homenaje al Profesor Doctor Don José Cerezo Mir (pp. 511-530). Madrid: Editorial Tecnos.

. (2004). Globalización, administrativización y expansión del derecho penal económico. En J. Terradillos y M. Acale (coords.), Temas del derecho penal económico. III Encuentro Hispano-Italiano de Derecho penal económico (pp. 219-240). Madrid: Editorial Trotta.

Vogel, J. (2005). Derecho penal y globalización. Anuario de la Facultad de Derecho de la Universidad Autónoma de Madrid, 9, 113-126.

- - - - (2008). La internacionalización del derecho penal y del proceso penal. Revista Penal, 22, 160-167.

Zúñiga, L. (2001). Política criminal. Madrid: Editorial Colex. 
